\title{
Situs Inversus Totalisli Hastada Laparoskopik Kolesistektomi
}

\section{Laparoscopic Cholecystectomy in a Patient with Situs Inversus Totalis}

\author{
Mustafa GiRGiN, ${ }^{1}$ Burhan Hakan KANAT, ${ }^{2}$ Refik AYTEN, ${ }^{1}$ Ziya ÇETINKAYA ${ }^{1}$ \\ ${ }^{1}$ Fırat Üniversitesi Tıp Fakültesi, Genel Cerrahi Anabilim Dalı, Elazığ \\ ${ }^{2}$ Elazığ Eğitim ve Araştırma Hastanesi, Genel Cerrahi Kliniği, Elazığ
}

\section{Özet}

Safra kesesi ameliyatını laparaskopik yöntem ile yapmak altın standart olarak kabul edilmektedir. Yaklaşık 1/10.00050.000 oranında görülen situs inversus totalis laparaskopik kolesistektomi için kontrendikasyon oluşturmadığı gibi altın standart olarak kabul edilmelidir. Bu yazıda, situs inversus totalisli hastada yapılan laparaskopik kolesistektomi sunuldu ve ek olarak ameliyat için yerleştirilen portların yerlerinin cerraha sağladığı faydalar değerlendirilmiştir.

Anahtar sözcükler: Laparaskopik kolesistektomi; kolelitiazis; situs inversus totalis.

\section{Summary}

The use of laparoscopy in gallbladder surgery is widely accepted as the gold standard. Situs inversus totalis, which is seen at a rate of 1/10.000-50.000 rate, does not have contraindication for laparoscopic cholecystectomy, and thus this method should be more frequently applied. We present a case of laparoscopic cholecystectomy in a patient with situs inversus totalis is presented and the benefits of port placement during surgery were evaluated.

Key words: Laparoscopic cholecystectomy; cholelithiasis; situs inversus totalis.

\section{Giriş}

Situs inversus totalis (SIT) 10.000-50.000 canlı doğumda bir görülen doğumsal bir anomalidir. ${ }^{[1]}$ SiT'li hastalarda cerrahi prosedürler sırasında çeşitli teknik güçlüklerle karşılaşılabilir. Özellikle laparoskopik operasyonlarda organların ayna görünümüne uyum güçlüğü cerrahın manevra kabiliyetini etkilemektedir. Bu yazıda, SiT'li hastada yapılan laparaskopik kolesistektomi sunuldu.

\section{Olgu Sunumu}

Yirmi beş yaşında kadın hasta 2.5 aydan beri epigastrik bölgede olan karın ağrısı ve dispepsi şikâyeti ile yapılan tetkikler sonucunda SiT ve kolelithiyazis tanısı aldı. Fizik bakısında kalp tepe vurusu sağda olup, karın sol üst kadranda hassasiyet mevcuttu. Laboratuvar tetkiklerinde özellik yoktu. Arka-ön akciğer grafisinde dekstrokardi mevcut ve mide fundus gazı sağdaydı (Şekil 1).

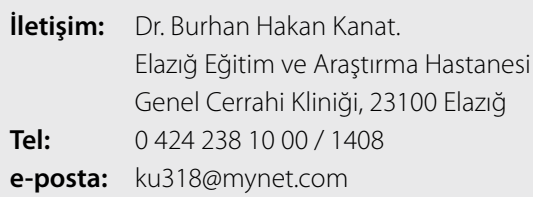

\section{Başvuru tarihi: $\quad 06.05 .2011$ \\ Kabul tarihi: $\quad 07.09 .2011$}

17. Ulusal Cerrahi Kongresi'nde e-poster olarak sunulmuştur (26-29 Mayıs 2010, Ankara). 


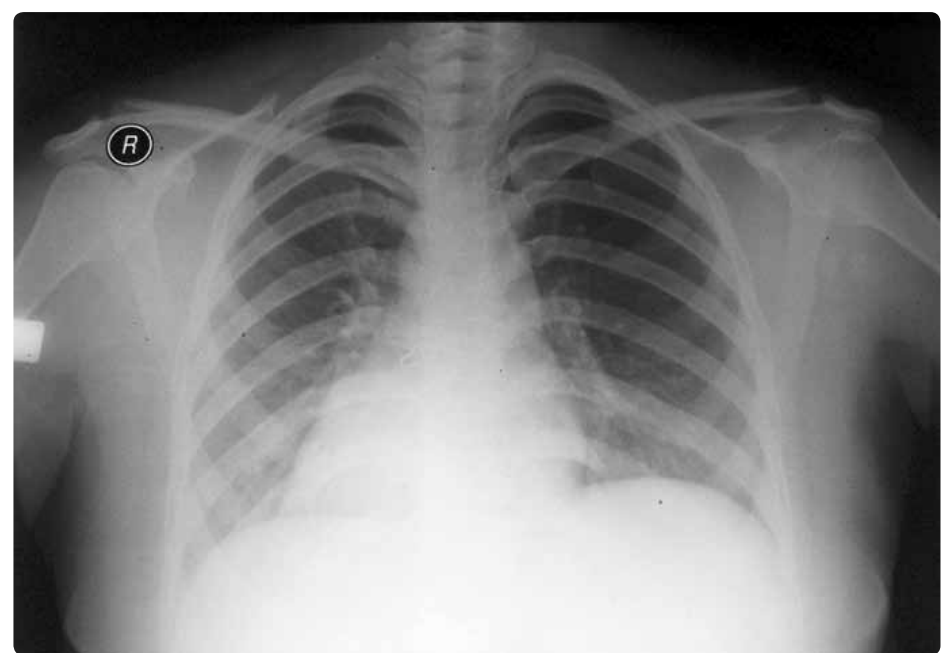

Şekil 1. Hastanın arka-ön akciğer grafisi.

Karın ultrasonografisinde (USG) dalak sağ üst kadranda, karaciğer ve safra kesesi sol üst kadranda yerleşimliydi. Safra kesesi cidar kalınlığı normal olup lümeninde milimetrik boyutta multipl kalküller vardı. Hastada olabilecek safra yolu patolojisi USG ile kontrol edilmiş olup koledok ve intrahepatik safra yolları normaldi. Ek görüntüleme yapılmadı. Rutin tetkiklerle anestezi kliniğinde değerlendirilen hastanın anestezi riski ASA II olarak belirlendi ve elektif operasyona alındı.

Operasyon odasının tasarımı hastaya uygun olarak hazırlandı. Cerrah ve birinci asistan hastanın sağına, masa hemşiresi ve ikinci asistan hastanın soluna yerleşti. Hastaya baş yukarı ve sağ yan olacak şekilde pozisyon verildi. Göbek altından yapılan $1 \mathrm{~cm}$ lik kesi ile verres iğnesi kullanılarak batın insufle edildi. Buradan 10 mm'lik trakar yardımı ile kamera batına yerleştirildi.

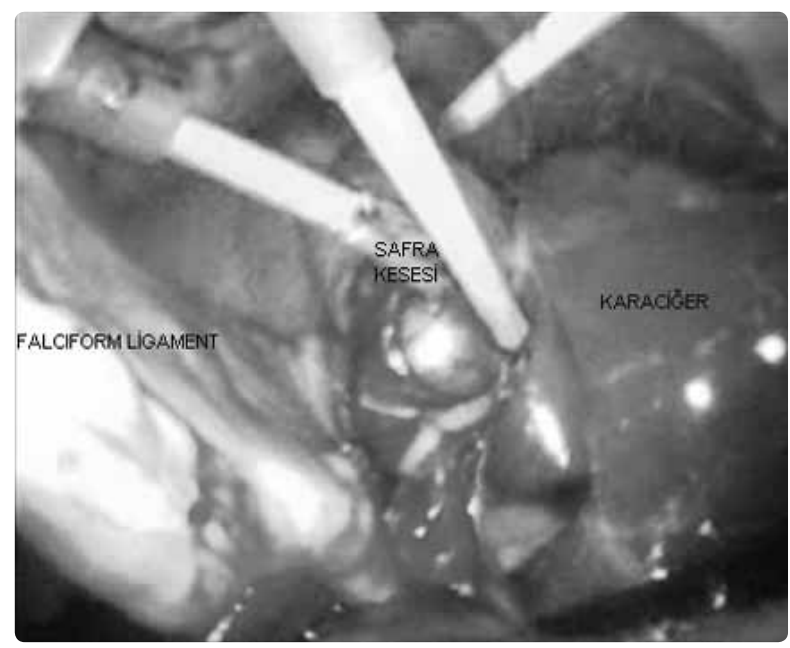

Şekil 2. Eksplorasyon.
Karın içi eksplorasyonda SiT mevcut olup safra kesesi normal büyüklükteydi ve ek patolojiye rastlanmadı (Şekil 2). Diğer 10 mm'lik trakar median epigastrik alana, ksifoidden yaklaşık $5 \mathrm{~cm}$ aşağıya yerleştirilirken diğer 2 adet 5 mm'lik trakarlar ise klasik laparoskopik kolesistektomideki yerleşim yerinin tam ayna aksi olacak şekilde sol tarafa yerleştirilerek 4 portlu teknik kullanıldı (Şekil 3). Calot üçgeni prepare edildikten sonra sistik kanal ve sistik arter izole edilerek klipslendi ve kesildi. Safra kesesi karaciğer yatağından disseke edilerek epigastrik bölgedeki kesiden karın dışına alındı. Kesede çok sayıda milimetrik taşlar mevcuttu. Ameliyat sonrası 2. gün hasta komplikasyonsuz olarak taburcu edildi.

\section{Tartışma}

Situs inversus totalis nadir görülen embriyolojik bir anomalidir ve genetik geçiş gösterir. ${ }^{[2]} \mathrm{Hem}$ göğüs hem de karın boşluğunu kapsayabileceği gibi sadece bir tanesini içerebilip parsiyel olabilmektedir. ${ }^{[3]}$ Bizim hastamızda total situs inversus mevcuttu. SiT embriyonik orta bağırsağın saat yönünün tersine $270^{\circ}$ döneceği yerde, saat yönüne $270^{\circ}$ dönmesi ile oluşur. Böylece tüm torasik ve abdominal visseral organlar normalde olmaları gereken lokalizasyonun orta hatta göre simetrik lokalizasyonuna yerleşirler. Yani situs inversus normalin aynadaki görüntüsüdür. Bu durumda safra kesesi de sol üst kadranda bulunur. ${ }^{[4]}$ SiT tanısı genellikle, bu olguya benzer şekilde, hayatın bir döneminde başka bir rahatsızlığa bağlı yapılan incelemeler esnasında tesadüfen konulur. Karın ve akciğer grafileri, oral ve intravenöz kontrastlı bilgisayarlı tomografi (BT), USG ve baryumlu çalışmalar tanı koymada yar- 


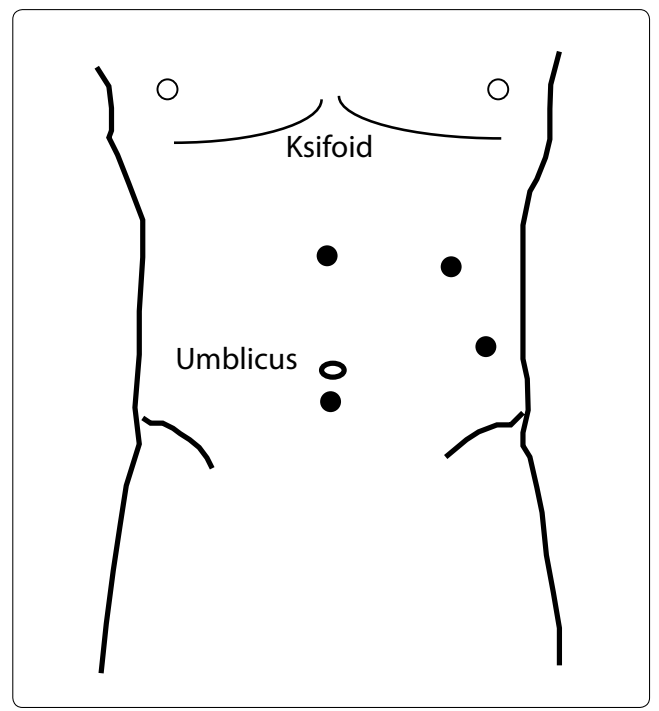

Şekil 3. Trokar giriş yerleri.

dımcı olabilir. ${ }^{[5]}$ Bizim hastamızda da tanı karın USG'si ile konulmuştu.

Situs inversus totalis safra kesesi taşı hastalığının insidansını arttırmaz. ${ }^{[6,7]}$ Situs inversuslu kişilerde akut kolesistit insidansında artış saptanmamıştır. Ekstrahepatik biliyer, venöz ve arteriyel anomaliler normal popülâsyonla aynıdır. ${ }^{[8,9]}$ Ancak daha az görülen tipi olan parsiyel situs inversus olgularında durum farkIıdır. Bunlarda bilier traktus ve vasküler anomaliler görülebilir. Bu nedenle parsiyel situs inversuslu olgularda ameliyat sırasında kolanjiyografi çekilmesi ve gerekirse açık cerrahiye yönlenilmesi önerilmektedir. ${ }^{[8]}$ Ya da bu hastalarda operasyon öncesi daha az invaziv olan manyetik rezonans kolanjiyografi (MRCP) yapılabilir. Bizim olgumuzda SiT mevcut olduğundan ve bu olgularda ek olarak hepatobiliyer anormallikler normal popülâsyonla aynı olduğundan MRCP'ye ya da başka bir ek görüntüleme yöntemine gerek duyulmamıştır. Bu olgularda intraoperatif kolanjiyografi endikasyonları normal hastalar ile aynıdır. Olgumuzda eksplorasyonda biliyer sistemle ilgili ek patoloji izlenmemiş olup kolanjiyografi yapılmamıştır.

Safra kesesi ameliyatını laparaskopik yöntem ile yapmak altın standart olarak kabul edilmektedir. ${ }^{[10]}$ Laparoskopik kolesistektominin (LK) minör ve majör birçok komplikasyonu vardır, ancak situs inversuslu olgularda özel bir komplikasyonu yoktur. ${ }^{[7]}$ Literatürde birçok olgu sunulmuştur. Bunların çoğuna sorunsuz olarak LK yapılmış ve hasta salah ile taburcu edilmiştir. LK endikasyonları SiT'li olgularda normal popülasyonla aynıdır. Machado ve Chopra'nın ${ }^{[1]}$ yapmış oldukları bir literatür taramasında 26 SIT'li, 3 parsiyel situs inversuslu ve 4 tanede türü bilinmeyen situs inversuslu hasta incelenmiştir. Bu hastaların tanıları, 19 hastada kronik kolesistit, 6 hastada akut kolesistit, 3 hastada biliyer kolik, 2 hastada kolanjit, 1 hastada mukosel, 1 hastada ampiyem ve 1 hastada da mikrolithiyazisdir. Bizim hastamızda da patolojik tanı kronik kolesistit olarak rapor edildi. Çalışmada 9 hasta erkek olup 1 tanesinde cinsiyet belirtilmemiş ve geri kalanını kadınlar oluşturmaktadır. Buna göre SiT'li hastalarda da bayanlarda kolelithiyazis görülme oranı daha yüksektir. Machado ve Chopra bu literatür taraması sonucunda SiT'li hastalarda LK'nin deneyimli cerrahlar tarafından güvenli olarak yapılabileceğini savunmuşlardır.

Laparoskopik kolesistektominin kesin ve rölatif kontrendikasyonları vardır. SiT kontrendikasyon oluşturmadığı gibi altın standart olarak kabul edilmelidir. Ancak portlar normalin ayna görüntüsünde yerleştirildiğinde sağ elli cerrahlar için orientasyon zorluğu nedeni ile sıkıntı yaratabilir ve komplikasyon riskini artırabilir. Ancak bu olgularda sol elini kullanan cerrahlar zorlanmayacaklardır. Olgumuz sağ elini kullanan cerrah tarafından opere edilmiştir. Biz bu olguda normalde ksifoide yakın olarak yerleştirilen 10 mm'lik portu göbeğin yaklaşık $5 \mathrm{~cm}$ yukarısından median epigastrik bölgeden yerleştirdik. Diğer portlar ise ayna görüntüsünden yerleştirildi. Bu yerleşim şekliyle sunulan diğer olgularla benzerlik göstermektedir. Böylece cerrahın oriyentasyonu daha rahat oldu. Literatürdeki diğer olgularda cerrah daha çok epigastrik bölgeden yerleştirilen porttan çalıştığı halde, bu olguda cerrah daha çok lateral portlardan girilen aletlerle çalıştı.

Sonuç olarak, SiT'li hastalarda laparaskopik yöntemler kontrendikasyon teşkil etmemektedir. Bu olgularda kullanılan aletlere uyum sağlanmasında yaşanan sıkıntıdan dolayı çakışmalar, manüplasyonlarda zorluklar yaşanması söz konusudur. Bu nedenle komplikasyon görülme riski artmaktadır. LK için ksifoid altından girilen portun, göbeğin 5-6 cm yukarısından ve orta hattan girilmesi ve sağ elli cerrahın daha çok lateral portları kullanması oriyentasyonu kolaylaştıracak, oluşabilecek tehlikeleri minimal düzeye indirecektir. Ancak klinik olarak gerekli görüldüğü durumlarda kolanjiyografi ve endoskopik retrograd kolanjio pankreatikografi yapılmalıdır. Ayrıca gerekli durumlarda açık cerrahiye dönmekten kaçınılmamalıdır. Komplikasyonsuz bir açık cerrahi, tehlikeli bir laparoskopik cerrahiye tercih edilmelidir. 


\section{Çıkar Çatışması}

Yazar(lar) çıkar çatışması olmadığını bildirmişlerdir.

\section{Kaynaklar}

1. Paunipagar BK, Rasalkar DD, Lonikar P, Chu WCW. Pancreatic neoplasm in a patient with situs inversus totalis: case report. J Hong Kong Col Radiol 2010;13(3):158-60.

2. Nursal TZ, Baykal A, Iret D, Aran O. Laparoscopic cholecystectomy in a patient with situs inversus totalis. J Laparoendosc Adv Surg Tech A 2001;11(4):239-41.

3. Al-Jumaily M, Hoche F. Laparoscopic cholecystectomy in situs inversus totalis: is it safe? J Laparoendosc Adv Surg Tech A 2001;11(4):229-31.

4. Katman Ü, Onur MR. Nadir bir akut karın nedeni: situs inversus totalis ve akut apandisit. İnönü Üniversitesi Tıp Fakültesi Dergisi 2007;4(2):137-9.

5. Güçer Fi, Baysal B, Çağlar M, Baş A, Kuru İ. Nadir bir akut karın olgusu: Situs inversus totalis ve akut apandisit.
Göztepe Tıp Dergisi 2010;25(4):182-4.

6. Özben V, Çarkman S, Aytaç E, Salihoğlu Z. Laparoscopic cholecystectomy in a patient with situs inversus totalis: case report. Firat Tıp Dergisi 2010;15(1):67-9.

7. Akcan A, Akyıldız H, Ekici F, Arıtaş Y. Kolelitiazisle birlikte olan bir total situs inversus olgusu. Erciyes Tıp Dergisi 2007;29(1):75-7.

8. Öngen A, Öngen C. Akut kolesistiti olan situs inversuslu bir hastada laparoskopik kolesistektomi: Olgu sunumu. S.D.Ü. Tıp Fak Derg 2010;17(2):25-6.

9. Yaghan RJ, Gharaibeh KI, Hammori S. Feasibility of laparoscopic cholecystectomy in situs inversus. J Laparoendosc Adv Surg Tech A 2001;11(4):233-7.

10. Himal HS. Minimally invasive (laparoscopic) surgery. Surg Endosc 2002;8:265-70.

11. Machado NO, Chopra P. Laparoscopic cholecystectomy in a patient with situs inversus totalis: feasibility and technical difficulties. JSLS 2006;10(3):386-91. 